\title{
Phlebotomine Sand Flies (Diptera: Psychodidae) Associated with the Appearance of Urban Leishmaniasis in the City of Sincelejo, Colombia
}

\author{
Eduar Elías Bejarano+ ${ }^{+}$Sandra Uribe, Winston Rojas, Iván Darío Vélez
}

Programa de Estudio y Control de Enfermedades Tropicales, Universidad de Antioquia, Cra. 50 A No. 63-85, A.A. 1226, Medellín, Colombia

Although once associated only with rural areas, the American leishmaniasis vectors now appear to be associated also with urban and suburban areas of the Neotropics. Following the appearance of the first autochthonous visceral and cutaneous leishmaniasis cases in the urban area of the city of Sincelejo, Colombia, a preliminary entomological survey of the sand fly species composition was performed using Shannon and CDC light traps. A total of 486 sand flies representing six Lutzomyia species were collected. L. evansi, L. panamensis and L. gomezi, known vectors of Leishmania spp. were the predominant sand fly species around dwellings. The finding of these species in relation to the appearance of the first cases of leishmaniasis in the city mentioned is discussed.

Key words: sand flies - Lutzomyia - urban leishmaniasis - Sincelejo - Colombia

Phlebotomine sand flies (Diptera: Psychodidae) play an important role in human diseases mainly as vectors of Leishmania spp., the etiologic agent of leishmaniasis. In recent years, the leishmaniases are spreading and new foci have been reported in the Americas. From a public health perspective, this is one of the most important emerging infectious diseases.

In Colombia, three epidemiological cycles of leishmaniasis have been described (Vélez et al. 2001). A sylvatic cycle mainly affecting active working age men, who get infected when entering the biotopes of the vector in order to exploit natural resources. A rural domestic cycle that is characterized as affecting the whole family nucleus, without distinction of sex, due to the fact that dwellings are located near the natural focus of transmission, thus propitiating the vector's arrival in the house. Recently, cases of cutaneous leishmaniasis (CL) in some urban zones of Colombia have been reported (Pardo et al. 1996, Sandoval et al. 1998, Vélez 2001), which shows the presence of a third cycle, a domestic urban one, previously unknown in the country.

Rapidly changing environmental conditions in many tropical regions caused by habitat destruction, such as that associated with deforestation/urbanization processes, have an enormous influence on vector populations and consequently on disease transmission. While some species may disappear, others become more abundant. Addi-

This research was supported by the Comité para el Desarrollo de la Investigación, Universidad de Antioquia (Grant CPT0019). ${ }^{+}$Corresponding author. Fax: +574-516.2675.

E-mail: bejarano@medicina.udea.edu.co or eduarelias@yahoo.com Received 2 October 2001

Accepted 3 April 2002 tionally, vector species that hitherto had no presence in these zones can arrive, adapting to anthropogenic environmental conditions. Lutzomyia longipalpis (Lutz \& Neiva, 1912), L. evansi (Nuñez-Tovar, 1924), L. whitmani (Antunes \& Coutinho, 1939) and L. intermedia (Lutz \& Neiva, 1912), for example, originally associated with sylvatic zones, appear currently adapted to domestic environments in urban and periurban areas of Neotropical regions (Walsh et al. 1993, Bejarano et al. 2001). As a result, outbreaks of CL and visceral leishmaniasis (VL) have appeared in urban environments of Latin America, in which they had no previous presence.

During 1999 and 2001, seven clinically and parasitologically confirmed cases of $\mathrm{CL}$, in which there was urban transmission, were recorded in the city of Sincelejo, Colombia. These cases corresponded to four adults and three children, who had not left the Sincelejo area for a period ranging from eight months to two years before the onset of the disease. In June 2001, the Regional Hospital's medical staff detected a 1.8 years old child with VL, born and resident of a neighborhood where transmission of VL had never been reported before. This motivated us to carry out an entomological survey in this urban area of the city.

The search for phlebotomine sand flies was carried out in the urban zone of the city of Sincelejo $\left(9^{\circ} 18^{\prime} \mathrm{N}, 75^{\circ}\right.$ $25^{\prime}$ W), Department of Sucre, Colombia, in June of 2001. This city is located at $218 \mathrm{~m}$ elevation, in a savannah covered region of the Colombian Caribbean coast. The average annual temperature for this city is $27^{\circ} \mathrm{C}$ and its mean annual rainfall, 1,050 $\mathrm{mm}$. For collections, the location selected was the same one in which the first cases of VL and CL had appeared. Founded more than 12 years ago, this neighborhood is located in urban southwestern Sincelejo, being one of the city's poorest areas. Ecologically, it is classified as tropical dry forest. Domestic animals found in the neighborhood include dogs, chickens and pigs. 
Opossums are very scarcely seen around human dwellings.

Sand flies were collected using an illuminated Shannon trap and two CDC light-traps placed in the vicinity of the family house during three consecutive nights of every week of June. The CDC traps were set $1 \mathrm{~m}$ above the ground and operated from 18 to $6 \mathrm{~h}$, representing $144 \mathrm{~h}$ of collection per trap. The Shannon trap was set $0.3 \mathrm{~m}$ above the ground and used by two individuals from 18 to $22 \mathrm{~h}$, representing 48 collector hours. Additionally, human bait collections were performed indoors.

Collected sand flies were placed in glass vials containing 70\% ethanol, then transferred to the PECET Laboratory of the Universidad de Antioquia. All the material was mounted on glass slides, using Canada balsam for the males and Berlese liquid for the females. Sand flies were identified using Young and Duncan's (1994) taxonomic key, coupled with a comparison with species from the Programa de Estudio y Control de Enfermedades Tropicales (PECET) standard collection.

A total of 486 specimens were captured and identified, which belonged to six species of the genus Lutzomyia: $L$. evansi, L. panamensis (Shannon, 1926), L. gomezi (Nitzulescu, 1931), L. cayennensis cayennensis (Floch \& Abonnenc, 1941), L. trinidadensis (Newstead, 1922) and L. rangeliana (Ortiz, 1952). The number of individuals captured for each species with relation to the type of trap used is shown in the Table. While sampling was taking place, some sand flies were coincidentally observed biting humans indoors; these were identified as $L$. evansi and L. panamensis.

For the first time, the presence of three vector species of Leishmania spp. with a known vectorial capacity: $L$. evansi, L. panamensis and L. gomezi, has been recorded in this neighborhood. These species possess public health antecedents in different Latin American regions. $L$. panamensis is a vector of Le. panamensis in Panama, $L$. braziliensis, in Guatemala and Venezuela (Christensen et al. 1983, Rodriguez et al. 1999), being considered a secondary vector of $C L$ in almost all the countries of Latin America in which it is present. L. gomezi is a highly anthropophilic species, also implied in the transmission of Le. braziliensis in Colombia and Venezuela (Vélez et al. 1991, Feliciangeli et al. 1994), and has been considered as a suspected vector of Le. panamensis in Panama (Christensen et al. 1983). In Colombia, this species is widely distributed, having been found in the periurban areas of those cities, in which outbreaks of CL had occurred (Vargas et al. 1991, Sandoval et al. 1998). L. evansi is an important vector of VL in rural areas of the Caribbean coast of Colombia and in some regions of Venezuela (Travi et al. 1996, Feliciangeli et al. 1999). L. cayennensis cayennensis, L. trinidadensis and L. rangeliana, captured in low numbers, do not offer up to now any importance from the medical point of view (Young \& Duncan 1994).

The presence of $L$. panamensis, $L$. gomezi and $L$. evansi in the urban area suggests that these species might be involved in the transmission of those CL and VL cases recorded in Sincelejo. The capture of specimens of $L$. evansi and L. panamensis in human biting activity indoors suggests an endophagic and anthropophilic behavior of this species in the zone sampled. Since the abundance of these species might eventually change, with it being greater in other periods of the year, it will be necessary to carry out seasonal variation and vectorial incrimination studies in this city, in which some basic questions should be answered, such as: Where are the urban breeding sites of the sand-fly vectors? What are the roles of the known reservoirs (dogs and opossums) in the urban domestic cycle of transmission of CL?

The presence of known vectors, together with the fact that cases of the disease have been recorded, make Sincelejo a zone of risk for the transmission of leishmaniasis, especially if ongoing deforestation/urbanization processes in the city are taken into consideration; human settlements of recent formation, lacking in organization, have grown in its surroundings, generally establishing their limits in pre-existing forest zones, or penetrating into them.

The appearance of leishmaniasis in the urban area of Sincelejo, added to previous outbreaks of the disease in urban zones of such cities as Bucaramanga, Remedios, Villeta, Durania, Leticia and Neiva (Vargas et al. 1991, Pardo et al. 1996, Sandoval et al. 1998, Vélez 2001), could be an indication that the classic epidemiological pattern of the leishmaniasis in Colombia is changing. This should also lead to a change in programs dedicated to epidemiological vigilance and control of the disease.

Genetic analysis of the sand flies collected from Sincelejo urban area and rural endemic leishmaniasis foci in the Colombian Caribbean coast is under way at the PECET of the Universidad de Antioquia to determine the gene flow, migration and role of some species in the transport of Leishmania from rural to urban environments.

TABLE

Number and percentage of sand fly species collected by type of trap in an urban area of Sincelejo, Colombia, June 2001

\begin{tabular}{|c|c|c|c|c|c|c|c|c|}
\hline \multirow[b]{2}{*}{ Sand fly species } & \multicolumn{2}{|c|}{ Shannon trap } & \multicolumn{2}{|c|}{ CDC light trap } & \multicolumn{2}{|c|}{ Human bait } & \multirow[t]{2}{*}{ Total } & \multirow[t]{2}{*}{$\%$} \\
\hline & $\mathrm{F}$ & M & $\mathrm{F}$ & M & $\mathrm{F}$ & M & & \\
\hline Lutzomyia evansi (Nuñez-Tovar, 1924) & 155 & 39 & 102 & 28 & 22 & 0 & 346 & 71.2 \\
\hline L. panamensis (Shannon, 1926) & 52 & 2 & 29 & 1 & 9 & 0 & 93 & 19.1 \\
\hline L. gomezi (Nitzulescu, 1931) & 21 & 2 & 10 & 0 & 0 & 0 & 33 & 6.8 \\
\hline L. cayennensis cayennensis (Floch \& Abonnenc, 1941) & 0 & 0 & 8 & 2 & 0 & 0 & 10 & 2.1 \\
\hline L. trinidadensis (Newstead, 1922) & 1 & 0 & 1 & 0 & 0 & 0 & 2 & 0.4 \\
\hline L. rangeliana (Ortiz, 1952) & 0 & 0 & 2 & 0 & 0 & 0 & 2 & 0.4 \\
\hline Total & \multicolumn{2}{|c|}{272} & \multicolumn{2}{|c|}{183} & \multicolumn{2}{|c|}{31} & 486 & 100 \\
\hline
\end{tabular}




\section{REFERENCES}

Bejarano EE, Uribe S, Rojas W, Vélez ID 2001. Presence of Lutzomyia evansi, a vector of American visceral leishmaniasis, in an urban area of the Colombian Caribbean coast. Trans $R$ Soc Trop Med Hyg 95: 27-28.

Christensen HA, Fairchild GB, Herrera A, Johnson CM, Young DG, Vásquez AN 1983. The ecology of cutaneous leishmaniasis in the Republic of Panama. J Med Entomol 20: 463484.

Feliciangeli MD, Rodríguez N, Bravo A, Arias F, Guzmán B 1994. Vectors of cutaneous leishmaniasis in North-central Venezuela. Med Vet Entomol 8: 317-324.

Feliciangeli MD, Rodríguez N, De Guglielmo Z, Rodríguez A 1999. The re-emergence of American visceral leishmaniasis in an old focus in Venezuela. II. Vectors and parasites. Parasite 6: 113-120.

Pardo RH, Farieta S, Munstermann LE, Ferro C 1996. Estudio preliminar de los flebótomos de Villeta y Quebradanegra, Cundinamarca: sus implicaciones en salud pública. Biomédica 16: 293-302.

Rodríguez N, Aguilar CM, Barrios MA, Barker DC 1999. Detection of Leishmania braziliensis in naturally infected individual sandflies by the polymerase chain reaction. Trans $R$ Soc Trop Med Hyg 93: 47-49.

Sandoval CM, Angulo VM, Gutiérrez R, Muñoz G, Ferro C 1998. Especies de Lutzomyia (Diptera: Psychodidae) posibles vectores de leishmaniasis en la ciudad de Bucaramanga, Santander, Colombia. Biomédica 18: 161-168.
Travi BL, Montoya J, Gallego J, Jaramillo C, Llano R, Velez ID 1996. Bionomics of Lutzomyia evansi (Diptera: Psychodidae) vector of visceral leishmaniasis in northern Colombia. J Med Entomol 33: 278-285.

Vargas GS, Alvarez G, Wolff M, López Y, Gómez ME 1991. Estudio de un foco de leishmaniasis en dos barrios de Remedios, Antioquia, 1990. Bol Epidemiol de Ant 16: 4859.

Vélez ID 2001. La leishmaniosis en Colombia: de la selva a la ciudad. Memorias, XXVIII Congreso de la Sociedad Colombiana de Entomología, Pereira, Colombia, p. 51-57.

Vélez ID, Hendrickx E, Robledo SM, Agudelo S 2001. Gender and cutaneous leishmaniasis in Colombia. Cad Saúde Pública 17: 171-180.

Vélez ID, Wolff M, Valderrama R, Escobar JP, Osorio L 1991. Community and environmental risk factors associated with cutaneous leishmaniasis in Montebello, Antioquia, Colombia. In P Wijeyaratne, T Goodman, C Espinal (eds), Leishmaniasis Control Strategies. A Critical Evaluation of IDRCSupported Research, Editorial International Development Research Center, Ottawa, p. 261-274.

Walsh JF, Molyneux DH, Birley MH 1993. Deforestation: effects on vector-borne disease. Parasitology 106 (Suppl.1): S55-75.

Young DG, Duncan MA 1994. Guide to identification and geographic distribution of Lutzomyia sand flies in Mexico, the West Indies, Central and South America (Diptera: Psychodidae). Mem Am Entomol Inst 54: 1-881. 
648 Sand Flies in Sincelejo, Colombia - Eduar Elías Bejarano et al. 